\title{
Superimposed polygonal approximation analysis comparing 2D photography and 3D scanned images of bite marks on human skin
}

Ain Ashraf Rizwal ${ }^{1}$, Nursyereen Azahar ${ }^{1}$, Nor Hidayah Reduwan ${ }^{1}$ and Mohd Yusmiaidil Putera Mohd Yusof ${ }^{1,2^{*}}$

\begin{abstract}
Background: Preservation of bite marks evidence has always been a major problem in forensic odontology due to progressive loss of details as time passes. The use of 2D photographs has been widely used to document forensic evidence and preserving bite marks; however, there are limitations to this method. This study aims to measure the accuracy of the 3D scanned image in comparison to 2D photograph registration of experimental bite marks. Thirty volunteers performed self-exertions of a bite mark on the respective forearm of subjects. A 2D photograph and 3D scanned image was immediately registered following bite mark exercise using a conventional camera and Afinia EinScan-Pro 2X PLUS Handheld 3D Scanner, respectively. The outlines of the bite mark were transformed into a polygonal shape. Next, the polygonal approximation analysis was performed by an arbitrary superimposition method. The difference between surface areas of both images was calculated (2D photographs 3D scanned images).

Results: A paired $t$ test was used to measure significance with $a=0.05$. The mean surface area of 2D photographs and 3D scanned images is $31.535 \mathrm{~cm}^{2}$ and $31.822 \mathrm{~cm}^{2}$, respectively. No statistical difference was found between both mean surface areas $\left(p>0.05\right.$ ). The mean error (ME) is $0.287 \pm 3.424 \mathrm{~cm}^{2}$ and the mean absolute error (MAE) is $1.733 \pm 1.149 \mathrm{~cm}^{2}$.

Conclusion: Bite marks registered with the 3D scanned image are comparable to the standard 2D photograph for bite mark evaluations. The use of a 3D scan may be adopted as a standard operating procedure in the forensic application, especially for evidence preservation.
\end{abstract}

\footnotetext{
* Correspondence: yusmiaidil@uitm.edu.my

${ }^{1}$ Center for Oral and Maxillofacial Diagnostics and Medicine Studies, Faculty

of Dentistry, Universiti Teknologi MARA, Sungai Buloh Campus, Selangor,

Malaysia

${ }^{2}$ Institute of Pathology, Laboratory and Forensic Medicine (I-PPerForM),

Universiti Teknologi MARA, Sungai Buloh Campus, Selangor, Malaysia
}

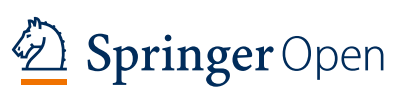

(c) The Author(s). 2021 Open Access This article is licensed under a Creative Commons Attribution 4.0 International License, which permits use, sharing, adaptation, distribution and reproduction in any medium or format, as long as you give appropriate credit to the original author(s) and the source, provide a link to the Creative Commons licence, and indicate if changes were made. The images or other third party material in this article are included in the article's Creative Commons licence, unless indicated otherwise in a credit line to the material. If material is not included in the article's Creative Commons licence and your intended use is not permitted by statutory regulation or exceeds the permitted use, you will need to obtain permission directly from the copyright holder. To view a copy of this licence, visit http://creativecommons.org/licenses/by/4.0/. 


\section{Highlights}

- 3D handheld scanner provides great details of the bite marks on the skin.

- No significant difference in mean surface areas between 3D scanned images and 2D photograph.

- Excess body hair may significantly hamper the surface details.

- 3D scanned image of bite mark is useful for forensic evidence preservation.

Keywords: 3D scanning, Bite marks, Forensic odontology

\section{Background}

A bite mark has been defined as "a pattern produced by human or animal dentitions and associated structures in any substance capable of being marked by these mean's" (Sheasby and MacDonald 2001; Clark 1993). In other words, a bite mark may be defined as a mark having occurred as a result of either a physical alteration in a medium caused by the contact of teeth or a representative pattern left in an object or tissue by the dental structures of an animal or human. Bite marks have been extensively used in forensic examinations as an adjunct examination to fingerprint and DNA identification (Kaur et al. 2013). Due to many cases of wrongful conviction based on bite mark conclusion, it is important to note that bite mark examination serves as a supplementary protocol and provides no alternative to the existing primary forensic identifiers. The individuality of the human dentition frequently allows the forensic odontologist to reach a strong opinion of association in cases of identification and bite mark analysis. However, the pattern it leaves as evidence can be mimicked by other people's dentition. Such analysis can often be useful during the investigation of violent crimes, especially those involving sexual assault (Gorea et al. 2014). In some crimes, bite mark evidence is the only evidence on which conviction has been achieved, particularly alleged rape and child abuse cases (Afsin et al. 2014). Bite marks have also been recovered from scenes of theft. Hence, bite marks obtained from a crime scene may be used as exclusive evidence in identifying the perpetrator by connecting the suspect to the crime scene and excluding the innocent.

However, in contrast to the bite marks individuality in forensic odontology, a problem related to this forensic evidence includes the preservation of bite marks evidence on human skin. This is due to its progressive loss of details as time passes. Factors such as the wound healing process in living individuals or the decomposition of dead tissue may influence the loss of further information in forensic bite marks (Fournier et al. 2019). Thus, it is essential to ensure that evidence relating to the injury is documented, collected, preserved, analyzed, and interpreted using scientifically accepted techniques. Up to date, the gold standard collection method from bite mark evidence is by photography (Hinchliffe 2011). Methods of analysis of bite marks from photographic evidence include odontometric triangle method, comparison technique, Vectron, and stereometric graphical analysis (Afsin et al. 2014). According to Modak, the most recent method of interpreting photographs up to date is by image perception software procedure (Afsin et al. 2014). Overlays are produced by layering images of the suspect's dentition with the original bite mark photograph to be compared and analyzed. However, 2D image of a bite mark by itself may introduce some limitations during the interpretation stage. Rajshekar mentioned two of the most encountered problem of using photographic bite marks in his study (Naether et al. 2012). Firstly, it is a 2-dimensional interpretation of 3dimensional information. Another factor is a photographic distortion, which will alter the bite mark appearance concerning photographic technique. Even when using recommended American Board of Forensic Odontology (ABFO) imaging techniques, the photographs of bite marks may not always be accurate and may be distorted (Naether et al. 2012).

Historically, 3D scanning holds a variety of use in forensic sciences. 3D scanning has been applied in forensic odontology for reconstructing skulls and jaws of victims of disasters, in researching and understanding dental anthropology, in the field of biometrics, and also in the analysis of bitemark (Evans et al. 2010; Naether et al. 2012). In 2013, Evans et al. compared 2D and 3D analytical methods to investigate the possibility of identifying a biting dentition (Evans et al. 2013). An optical scanner was used to produce 3D images of impressions of dentitions made on four different types of materials. The authors concluded that $3 \mathrm{D}$ analytical methods were superior to the $2 \mathrm{D}$ method employed in this study and that it was possible to identify the biting dentition in most cases using 3D method. This study aims to measure the accuracy of rapid prototyping 3D scanned image in comparison to 2D photograph registration of experimental bite marks. 


\section{Methods}

The current study is a pilot observational cross-sectional study in which thirty subjects (10 males and 20 females) with a complete set of natural upper and lower anterior teeth were selected for this study. Subjects with orthodontic appliances, intraoral prosthesis, loss of anterior tooth structure, developmental tooth anomalies, or skin conditions that can distort the bite marks in the area of interest were excluded from the study. Prior to the procedure, a consent form was given to each subject to explain the purpose and risk associated with this study. Participants were the dental undergraduate students consisting of equal number of men and women. Selfexertions of a bite mark on the respective forearm of subjects were performed, and a 2D photograph and 3D scanned image was immediately registered following bite mark exercise using a conventional DSLR camera (Nikon D3500) and Afinia EinScan-Pro 2X PLUS Handheld 3D Scanner, respectively. The 2D picture was taken per the ABFO guidelines, which include using a highquality camera and having sufficient resolution. The most important aspect of collecting photographic evidence is the position of the camera to the bite mark. To prevent dimensional bias, a forearm rest was constructed to reproduce the same angulation during photography. The photograph was taken perpendicular to the bite mark using a tripod bubble level to minimize any error involving angular distortion, which may cause changes in the appearance of the bite mark in the acquired photograph in terms of shape and dimensions of the bite mark.

The 3D scanned image was then immediately recorded using Afinia EinScan-Pro 2X PLUS Handheld 3D Scanner (scan speed: $20 \mathrm{fps}$ 1,100,000 points/s 100 data capture lines, scan accuracy: $0.04 \mathrm{~mm}$, point distance: $0.2-3$ $\mathrm{mm}$, working center distance: $510 \mathrm{~mm}$ ). The scan settings were set according to the manufacturer's recommendation regarding orientation, resolution, object size, color, frame rate, and target range. The scanning of the bite marks was made sure to cover the entire indentation of dentition registered onto the skin. From the scanned 3D image, the 2D image was obtained by positioning the bite mark as the $2 \mathrm{D}$ photograph positioning of the respective bite mark. Acquired 2D photographs and 3D scanned images of bite marks are mostly circular to oval. A straight line from the obtained bite mark was drawn mesiodistally using Adobe Photoshop ${ }^{\circ}$ software on each tooth indentation present; extending from the darkest point (indicating the deepest indentation) of the mesial tooth connecting to the darkest point that was marked on the distal and midpoint of the mesiodistal width of the tooth (Fig. 1). The midpoint obtained was connected to the center of the contralateral tooth (e.g., maxillary right central incisor with mandibular

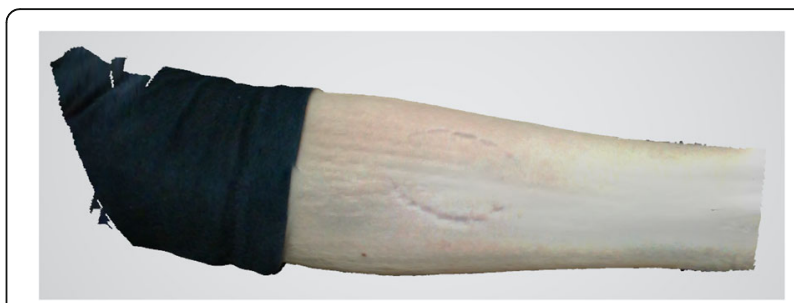

Fig. 1 3D scanned bite mark image

left central incisor). The resulting images are as depicted in Fig. 2. Next, the polygonal approximation analysis was performed by an arbitrary superimposition method. The polygonal shape was constructed following the outline of the marked midpoint, and the surface area of both 3D images and 2D photographs polygonal was brought into comparison. The surface area was calculated using the width and length radiuses of oval shown in Fig. 3.

Prior to the superimposition method, intra- and interobserver reliability scores were performed for the landmark placements based on the out-of-sample participants. The inter-observer reliability score was compared with a board-certified forensic odontologist of more than 10 years of experience.

The ethical approval for this study has been obtained by the Institutional Review Board (REC/169/18). The values and surface areas were tabulated in Microsoft Excel following the measurements using Adobe Photoshop software.

\section{Statistical analysis}

Quantitative data was entered for computer analysis using the Statistical Package for Social Sciences software program (SPSS) version 23 and evaluated on a 0.05 significance level. The difference between surface areas of both images was tabulated (2D photographs-3D scanned images). Mean error (ME) and mean absolute error (MAE) was determined from the obtained results. A paired t-test was used to measure significance with $\alpha=$ 0.05 to analyze the accuracy of 3D scanned image in comparison to 2D photograph registration of experimental bite marks. Intra- and inter-observer reliability scores were measured using kappa statistics.

\section{Results}

The mean surface area of all 30 participants' 2D photographs and 3D scanned images is $19.983 \mathrm{~cm}^{2}$ and 19.862 $\mathrm{cm}^{2}$, respectively. The mean error (ME) is $0.120 \pm 1.573$ $\mathrm{cm}^{2}$ and the mean absolute error (MAE) is $1.106 \pm$ $1.106 \mathrm{~cm}^{2}$. The means were compared using the paired $t$ test (Table 1). There is no statistical difference found between both areas of 2D photographs and 3D scanned images $(p>0.05)$. The intra-observer and inter-observer 

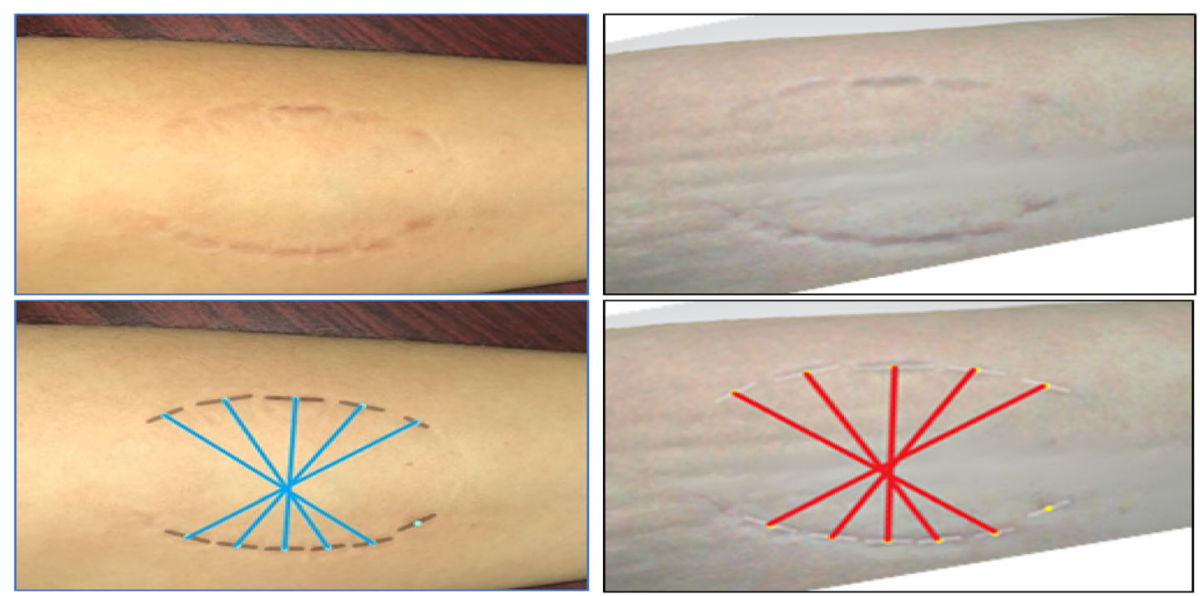

Fig. 2 2D photograph and 3D scanned image before and after landmark marking

scores for the landmark placements of the superimposition yielded weighted kappa coefficients of 0.93 and 0.85 , respectively.

\section{Discussion}

Based on the results and analysis, a large portion of the samples did not demonstrate any significant difference when comparing the surface areas of $2 \mathrm{D}$ photographs and 3D scanned images. A minor difference can be noted in every sample, which may be a result of photographic distortion. It is important to note that the depth of the bite mark indentation in this pilot study was not measured due to compliance issue. The volunteers were not able to observe the multiple designated time frames for indentation depth re-measurement. Further controlled research is necessary to validate this aspect of bite mark's information preservation. To our knowledge, there are no controlled trials involving human subjects on bite mark changes to date. There have been articles that are introducing 3D imaging as forensic evidence preservation technique with no actual experimental research studied (Carew and Errickson 2020; Raneri 2018).

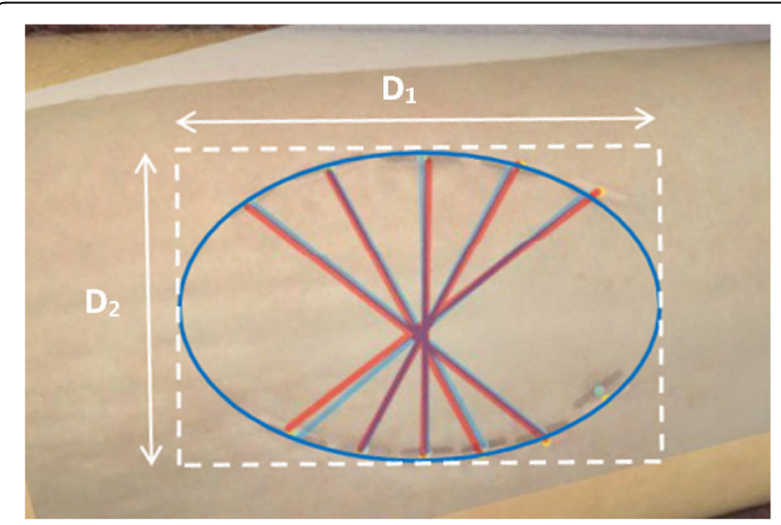

Fig. 3 Diameter for surface area calculation
It is expected that such study design requires vigorous ethical oversight from the institutional review board that could dampen the research effort altogether.

3D scanning devices use two distinctive techniques, passive and active. In our research, we used the passive method, which was based on stereo-photogrammetry. This method gathers data from reflected light already present in the scene, for instance, fluorescent light in a room or natural sunlight. The same concept is also used in many smartphones nowadays, such as the iPhone Light Detection and Ranging (LiDAR). This is particularly useful in cases involving bite marks where it is important to record the evidence as soon as possible. The active process, on the other hand, projects lasers of either structured or unstructured light. The structured light projects a grid onto the object for further 3D reconstruction and a more accurate dimension for data collection.

It is also pertinent to establish a capability framework that enables an operator to perform specific roles within a given range of functions as a crime scene reconstruction specialist. The $3 \mathrm{D}$ scanning process in our current research was performed by a single operator who had prior training in operating 3D scanner. As the process requires a steep learning curve, it is envisaged that the training in 3D scanning process will need to be included in developing human capital within the forensic odontology fraternity.

There was a small number of samples in the present study, where surface data was loss due to the presence of excess body hair $(n=4)$. These subjects were

Table 1 Mean difference between 3D and 2D surface areas

\begin{tabular}{llllll}
\hline Area & Mean & $\boldsymbol{N}$ & SD & SE & Significance \\
\hline 3D area & 19.98 & 30 & 18.313 & 3.344 & 0.467 \\
2D area & 19.86 & 30 & 17.787 & 3.247 & \\
\hline
\end{tabular}


removed from the study, as no details were available for subsequent evaluations by the images produced. Therefore, it is recommended that the excess body hair be shaved before 3D scanning procedure to avoid inadequate scan surface coverage.

\section{Conclusion}

In conclusion, utilizing 3D scanning techniques as an alternative for forensic evidence preservation is comparable to the standard 2D photograph. The 3D scanned images would also improve the preserving information of the bite mark should re-examination is required at a later time.

\section{Abbreviations}

2D: 2-dimension; 3D: 3-dimension; ME: Mean error; MAE: Mean absolute error; DNA: Deoxyribonucleic acid; ABFO: American Board of Forensic Odontology; SPSS: Statistical Package for Social Sciences software; LiDAR: Light Detection and Ranging

\section{Acknowledgements}

None

\section{Authors' contributions}

AAR, NA, and MYPMY conceived the idea of writing this paper. AAR, NA, NR, and MYPMY were involved in the design of the work and analysis and interpretation of the data. AAR and NA wrote the initial draft of the manuscript. AAR, NA, NR, and MYPMY have read and approved the final version of the manuscript. All authors have equally participated in this work. All authors read and approved the final manuscript.

\section{Funding}

LESTARI Research Grant, Universiti Teknologi MARA Malaysia [600-IRMI 5/3/ LESTARI (011/2019)]. The funding includes the purchasing of the research instruments, analysis of the data, and writing of the manuscript.

\section{Availability of data and materials}

The dataset used and analyzed during the current study is available from the corresponding author on reasonable request.

\section{Declarations}

\section{Ethics approval and consent to participate}

This study was approved by the Institutional Research Ethics Committee of Universiti Teknologi MARA (UiTM) with reference no. REC/169/18. Written informed consent was obtained from the participants to perform experiments, collect samples, and use for scientific purposes.

\section{Consent for publication}

Not required by the ethics committee.

\section{Competing interests}

The authors declare that they have no competing interests.

Received: 15 February 2021 Accepted: 13 August 2021

Published online: 23 August 2021

\section{References}

Afsin H, Karadayi B, Cagdir SA, Ozaslan A (2014) Role of bite mark characteristics and localizations in finding an assailant. J Forensic Dent Sci 6(3):202-206 https://doi.org/10.4103/0975-1475.137078

Carew RM, Errickson D (2020) An Overview of 3D Printing in Forensic Science: The Tangible Third-Dimension. J Forensic Sci 65(5):1752-1760 https://doi. org/10.1111/1556-4029.14442

Clark DH (1993) Practical Forensic Odontology. Med Leg J 61(2):114-114 https:// doi.org/10.1177/002581729306100208
Evans S, Jones C, Plassmann P (2010) 3D imaging in forensic odontology. J Vis Commun Med 33(2):63-68. https://doi.org/10.3109/17453054.2010.481780

Evans ST, Jones C, Plassmann P (2013) 3D imaging for bite mark analysis. Imaging Sci J 61(4):351-360 https://doi.org/10.1179/1743131X11Y.0000000054

Fournier G, Savall F, Nasr K, Telmon N, Maret D (2019) Three-dimensional analysis of bitemarks using an intraoral scanner. Forensic Sci Int 301:1-5 https://doi. org/10.1016/j.forsciint.2019.05.006

Gorea RK, Jasuja OP, Abuderman AA, Gorea A (2014) Bite marks on skin and clay: A comparative analysis. Egypt J Forensic Sci 4(4):124-128 https://doi.org/10.1 016/j.ejfs.2014.09.002

Hinchliffe J (2011) Forensic odontology, part 4. Human bite marks. Br Dent J 210(8):363-368 https://doi.org/10.1038/sj.bdj.2011.285

Kaur S, Krishan K, Chatterjee PM, \& Kanchan T (2013) Analysis and identification of bite marks in forensic casework. Oral Health Dent Manag. 12(3):127-131. Retrieved from https://www.ncbi.nlm.nih.gov/pubmed/24352302

Naether S, Buck U, Campana L, Breitbeck R, Thali M (2012) The examination and identification of bite marks in foods using 3D scanning and 3D comparison methods. Int J Legal Med 126(1):89-95 https://doi.org/10.1007/s00414-0110580-7

Raneri D (2018) Enhancing forensic investigation through the use of modern three-dimensional (3D) imaging technologies for crime scene reconstruction. Aust J Forensic Sci 50(6):697-707 https://doi.org/10.1080/00450618.201 8.1424245

Sheasby DR, MacDonald DG (2001) A forensic classification of distortion in human bite marks. Forensic Sci Int 122(1):75-78. https://doi.org/10.1016/s03 79-0738(01)00433-9

\section{Publisher's Note}

Springer Nature remains neutral with regard to jurisdictional claims in published maps and institutional affiliations.

\section{Submit your manuscript to a SpringerOpen ${ }^{\circ}$ journal and benefit from:}

- Convenient online submission

- Rigorous peer review

- Open access: articles freely available online

High visibility within the field

- Retaining the copyright to your article

Submit your next manuscript at $\boldsymbol{\nabla}$ springeropen.com 